\title{
The Role of Multicultural Information in Experiential Learning
}

By Lan Shen

\section{Abstract}

This paper is based on the author's empirical experience in assisting cultural immersion programs through developing multicultural collections, promoting diversity resources, and creating a supportive information environment for faculty and students. After summarizing the significance, goals, learning objectives, and program models of cultural immersion, this paper discusses the principles of selecting multicultural materials, cultural immersion information, and practical tips on designing and maintaining web-based sources. This paper also addresses the issues of developing an effective mechanism to build collaboration between librarians and faculty members with respect to cultural immersion curricula and to create an open information environment for disseminating multicultural resources for experiential learning courses.

\section{Introduction}

Experiential learning is emerging as a significant component of student learning, designed to combine and balance theoretic learning with practical operation. According to A. Kolb and D. Kolb (2005), John Dewey, Kurt Lewin, and others who were the founders of experiential learning theory have defined experiential education as a learning process of relearning, conflict solving, adaptation, synergetic transactions, and knowledge creation (p. 194).

As one of the seven main types of experiential learning, cultural immersion is defined as "a travel experience which involves both academic learning and value added experiences designed to enhance student awareness of cultural differences" (Purdue University Calumet, 2009). In Kitsantas's opinion (2004), cultural immersion should be defined as "all educational programs that take place outside the geographical boundaries of the country of origin" (p. 441). To a larger extent, multicultural education has been addressed by most American universities' missions and strategic plans because multiculturalism "is not only the key issue across disciplines including education but also the way people live their lives in an increasingly diversified world" (He, Phillion, \& Connelly, 2005, p. 291). Moreover, enhancing the awareness, knowledge, and skills of students has become an important priority for educators of diversity (Tyler, 1999, p. 154).

In response to these new challenges, Purdue University Calumet (PUC) has launched an innovative effort to require all undergraduate students to take six credits of Experiential Learning (EXL) courses as a graduation requirement. In support of this new requirement, the U.S. Department of Education awarded PUC a Title III grant partially to develop EXL, multicultural collection and resources on cultural immersion/study abroad.

This paper is based on the author's experience in assisting cultural immersion programs through developing multicultural collections, promoting diversity resources, and creating a supportive information environment for faculty and students. After clarifying the significance, goals, learning objectives, and popular models of cultural immersion, the paper addresses the principles of selecting and collecting cultural immersion information. Furthermore, the process of designing and maintaining cultural immersion web-based sources is discussed and evaluated. The paper also focuses on the issues of developing effective methods to build collaboration between librarians and faculty members for cultural immersion curricula. At the end, this paper discusses various ways of creating an open information environment to disseminate multicultural resources for EXL courses. To emphasize the role of cultural immersion in EXL programs, this paper concentrates on the challenges that librarians face when preparing students to study in culturally diverse environments and outlines practical suggestions for using cultural immersion information to support experiential learning. 


\section{Significance and Goals of Cultural Immersion Programs}

To select appropriate information for cultural immersion, it is essential to understand current trends in cultural immersion programs in the United States. Since the 1980s, the popularity of study abroad programs has been propelled by an increasingly diversified globalization. Cultural immersion or study abroad programs have become "increasingly legitimized as forms of experiential learning" because they are "turned into deep learning through a reflective process whereby the student assimilates lessons" (Gray, Murdock, \& Stebbins, 2002, p. 45). As a result, enrollment in study abroad programs between 2000 and 2004 has increased by 45 percent (Kitsantas, 2004, p. 441). According to the Institute of International Education, during the 2006-07 academic year, the number of study abroad participants increased to a total of 241,791 , representing a $150 \%$ increase over the 1996-97 academic year (Institute of International Education, 2008).

Furthermore, more and more developing countries are willing to accommodate American students through cultural immersion programs. The number of American students traveling to China, Argentina, South Africa, Ecuador and India, for instance, each increased by more than 20 percent in 2006-2007. However, Europe continued to host the largest percentage of American students (57\%), while Latin America hosted 15\%, Asia hosted $10 \%$, Oceania hosted 6\%, and Africa hosted 4\% (Institute of International Education, 2008). With respect to the term of study abroad programs, an Open Doors report found that $36 \%$ of American students studying abroad selected semester-long programs while 55\% chose shortterm programs, including summer, January term, and two to eight week programs during the academic year. Among these programs, the top three fields of study abroad are the social sciences $(21 \%)$, business and management $(19 \%)$, and humanities (13\%) (Institute of International Education, 2008).

The impressive development of study abroad programs has validated the American Library
Association's Diversity Action and Inclusion Plan, which believes that the "library should provide a high level of information service regarding language origin, regional and geographic background, economic class, education, learning and communication styles, and sexual orientation and personal lifestyle" (Alexander, 2006, p. 128). Alexander (2006) contends that multicultural literature provided by libraries could help students learn about various cultures (p. 128) because "multicultural materials can provide windows on the many cultures of the world" through creating a diverse library collection (Agosto, 2007, p. 28).

Meanwhile, the growth of new technology in libraries has provided the driving force in disseminating multicultural information effectively. At present, "electronic cross-cultural projects have promised to increase cultural sensitivity and awareness as they develop the skills and experiences needed in a global society" (Merryfield, 2003). After being a librarian for several years at Ohio State University, Merry Merryfield (2003) was convinced that electronic tools are critical for librarians and instructors who "value cross-cultural experiences, skills, and knowledge in local, national, and global contexts". In addition, Agosto recommends the Multicultural Review (www.mcreview.com), a web-based journal published quarterly by the Goldman Group, as a useful reference for a diverse library collection (Agosto, 2007, p. 29).

Additionally, librarians need to understand the goals of cultural immersion programs when selecting accurate and update information. As Tyler argues, "nowhere is the need for a new focus on experiential learning greater than in the area of multicultural and diversity education" since multicultural education has an implied or explicit goal of "developing attitudes and behaviors consistent with the acceptance and celebration of human diversity" (Tyler, 1999, p. 162). The cultural immersion programs at Missouri Southern University, for example, are designed to help students have an accurate understanding of international issues on history, geography, language, literature, philosophy, economics, and politics (Gray, Murdock, \& Stebbins, 2002, p. 47). 
More concisely, their cultural immersion programs are providing an invaluable opportunity to expand the foreign language program and develop new courses with an international focus (Gray, Murdock, \& Stebbins, 2002, p. 46). As a result, study abroad programs enhance students' multicultural skills, social capabilities, and professional knowledge on the subject matter (Kitsantas, 2004, p. 441). As Reimers (2009) argued, college students should improve their global competency which includes positive attitude, an ability of speaking foreign languages, and deep knowledge and understanding of world (pp. 184-85). Needless to say, the library is capable of providing the in-depth multicultural information covering various perspectives, regions, and languages.

The goals of study abroad are crucial in determining learning objectives. According to Gray and others, learning objectives should include: 1) understanding of how cultures and societies around the world have formed, sustained, and evolved; 2) empathy for the values and perspectives of cultures other than their own and an awareness of international and multicultural influences in their own lives; 3) ability to identify and discuss international issues and other cultures; 4) communicative competence in a second or third language; and 5) experience or desire to experience a culture other than their own (Gray, Murdock, \& Stebbins, 2002, p. 47). However, Paige (2007) argues that five dimensions of cultural learning should be addressed: 1) learning about the self as a cultural being; 2) learning about the elements of culture; 3 ) culture-specific learning; 4) culture-general learning; and 5) learning about learning (p. 40). To understand a specific culture, seeing for oneself is much better than hearing from others or learning from books. One of the key learning objectives of cultural immersion is authenticity, which requires "a real world context and/or be useful and meaningful in reference to an applied setting or situation" (National Society for Experiential Education, 2008).

In addition to understanding the goals and learning objectives of study abroad programs, librarians need to learn the common models of study abroad programs that are critical in helping design the necessary reading materials. Generally speaking, current study abroad models are comprised of: 1) short-term travel abroad (attending seminars); 2) short-term study abroad (one to six week language and/or comparative cultural studies during spring break or summer); 3) on-site classes (regular courses providing for cultural immersion as well as a hands-on academic experience); 4) student teaching (students in education major teaching courses in K-12 schools abroad); 5) long-term study abroad (one semester or one year course) (Gray, Murdock, \& Stebbins, 2002, p. 46); and 6) joint degree programs. Librarian should collect and provide helpful reading materials required by the different cultural immersion models respectively.

\section{Principles and Design of Cultural Immersion Online Information}

Following the aforementioned definitions, goals, learning objectives, and models of cultural immersion programs, the principles of designing, selecting, and disseminating web-based multicultural and cultural immersion information should be addressed. For Agosto (2001), quality multicultural resources and assessment should follow five major principles: accuracy, expertise, respect, purpose, and quality (p. 29).

The author of this article prefers to establish knowledge, sensitivity, and concision as three key guidelines for selecting online resources on cultural immersion. First of all, it is critical to have knowledgeable librarians who are capable of providing reliable and comprehensive online information. One of the reasons for the misunderstandings of different cultures is people's unfamiliarity with the nature of cultural differences. Thus, librarians need appropriate training on multicultural issues and comprehensive research on the subjects before attempting to create online information on cultural immersion. According to Tyler (1999), librarians maximize their learning through "carefully defining the learning objective in advance and being knowledgeable of media options" (p. 160). 
Second, sensitivity is vital for multicultural information collection. Librarians should limit, or even eliminate, their own biases and stereotypes against a particular race, nationality, or culture. Tyler (1999) believes that "stereotypes and personal biases can negatively affect instructors' and students' interactions with others." Therefore, librarians should be sensitive to different cultures while examining their own biases toward diverse groups (p. 161). Also, a minority librarian does not necessarily ensure appropriate and value-free selection because he/she could have a much stronger bias if his/her culture has experienced historical confrontations with other cultures. Thus, lack of cultural sensibilities will not only cause cultural misunderstanding, but also create unnecessary cultural confrontations.

Third, the online information collected must be concise and simple. In an effort to provide readerfriendly resources to students and faculty, the website content must be accessible and easy to understand. Living in an age of information explosion, people continue to face the challenges of information reliability. Thus, libraries need to provide accurate and concise online information in order to sort out the real gold from the sand. After all, speaking of information collections, more does not mean good. The information should be clearly divided into different categories to cater to different patrons, such as students, faculty, parents, and the general community. The advantages of online materials are their accessibility, readability, and unlimited space.

After all, excessively complex contents will discourage students and faculty from visiting the website and defeat the original purpose of developing online information.

Following these principles, this author has designed and maintained a cultural immersion website for teaching and learning since 2007. First of all, the website is comprised of four sections: connecting the world (including the introduction of history and politics for each country), understanding multicultural societies (focus on cultural tradition, cultural uniqueness, and heritages), exploring opportunities (study abroad opportunities and scholarship), and living in the other parts of the world (tips, travel guides, etc). Each section includes selected books and related web resources. Instead of selecting leading research monographs on the subject in the section of books, the website lists a variety of popular multicultural reading materials that expand cultural understanding by explaining the history, cultural myths, and psychological factors. For instance, it is feasible to list the Culture Shock Series, which are cultural etiquette guides covering various countries around the world. It also provides an interesting cultural course on the dos and don'ts in a foreign environment. It includes first impressions, cultural quizzes, and further reading recommendations that are both useful and humorous. Reference materials, such as the Culture Gram World Edition and the Encyclopedia of Food and Culture, are also selected as valuable multicultural background information.

In addition to books, the key component of the website is the selected web information regarding to the most important aspects of multicultural and study abroad. After evaluating hundreds of related websites, this author selected more than 30 websites and divided them into four informative categories. The first category is general information on different countries and cultures. The second one contains specific cultural traditions of various countries, particularly of those that American students are not familiar with, such as countries in the Middle East and Asia.

Meanwhile, given that experiential education and cultural immersion are quite new for a regional campus like PUC, the website lists useful links for students who have never experienced international travel. These resources serve as a practical guide to help students make the most of their experience in a new culture environment.

The third category includes wide-ranging opportunities for scholarships and grants for students who cannot afford expensive international travel. Given the current tough economic climate, external financial support is vital to ensure the survival of study abroad programs. The fourth provides information about 
study abroad travel guidelines, including safety, weather, travel tips, common foreign phrases, etc. For instance, it is critical to post travel alert information provided by the U.S. Department of State and by the World Health Organization (WHO).

\section{Promotion and Dissemination of Cultural Immersion Curriculum}

Once the website is designed and published, it is critical to promote the website and disseminate the information across campus. Both librarians and faculty need to work together to effectively promote the cultural immersion curriculum.

Defined by Scott (2004), the curriculum "refers to programs of teaching and learning which take place in formal settings" (p. vii). In Gorski's view (2001), multicultural education is designed to promote the "ideals of social justice and educational equity" (p. 9) through instructional practices and curricula based on notions of active, interactive, inclusive, and collaborative learning and teaching. Instructors are encouraged to use these resources to end the "massive injustices of traditional, Eurocentric and male-centric curricula" (Gorski, 2001, p. 39). Furthermore, a curriculum that integrates multicultural resources across disciplinary boundaries will provide invaluable perspectives and interpretations on the sensitive issues (Agosto, 2007, p. 29).

Given the fact that many foreign countries, such as those in Eastern Europe, have experienced numerous political, economic and cultural changes since 1989, and their territories and governments may have been reshaped before American textbooks have been revised. Therefore, librarians should provide updated information to revise the current multicultural curricula. For instance, librarians should "integrate multicultural and bilingual materials into the library curriculum" by means of sponsoring guest lecturers, introducing new multicultural books, and presenting programs on minority cultures and languages. Particularly, librarians should help familiarize students with different cultures through examining multicultural and bilingual materials (Agosto, 2007, p. 29). Equally important, librarians should "create a visually diverse library environment by including people of all backgrounds in graphic depictions in library décor, as well as by placing objects that represent different cultures around the library" (Agosto, 2007, p. 29). To be sure, librarians are not only information collectors and distributors, but also instructors and facilitators as teaching is an inherent part of reference services provided by librarians (Connor, 2008, p. xxi).

In light of the aforementioned requirements, librarians should make every effort to effectively use website information and infuse that information into multicultural curricula. In doing so, librarians should work with faculty to design and implement the following teaching and learning programs on cultural immersion.

Since cultural immersion is a long process that involves pre-trip preparation, in-country travel, and post-trip experience, librarians need to work with faculty to facilitate pre-trip workshops aimed at discovering the American cultural identity, learning basic cultural knowledge, and limiting existing stereotypes. Based on Kitsantas' experience, "cross-cultural training prior to departure (e.g., formal workshops) is needed to introduce sojourners to the importance of culture, and to the inevitable stresses that occur as people attempt to adjust to their new setting." The proposed pre-trip workshop, in Kitsantas' view (2004), should focus on "awareness of culture and cultural differences, factual knowledge necessary for adjustment, challenges to people's emotional balance that intercultural experiences unavoidably bring, and opportunities to practice skills and behaviors that can assist people's adjustment" ( $p$. 442).

To ensure a successful workshop, students should be required to read information related to the foreign culture and society and be encouraged to bring back the relevant resources from foreign countries once the international trip is completed. According to Merryfield's experience (2003), she invited three Somali women to talk about Somali culture and norms at a pre-trip workshop. Most importantly, these native guests demonstrated the uniquely Somali table manners at a nearby Somali 
restaurant, including eating with the right hand and never the left, eating from the common dish directly in front of you, and so on.

Besides, after learning some basic information about the specific culture, role-playing is an effective way of improving mutual understanding of different cultures (Pedersen, 2004, p. 23). For instance, China's one-child policy is extremely controversial. The workshop can divide students into two groups to discuss this issue. One would take a stand in favor of the one-child policy and argue from an economic perspective in terms of the need for population control; the other would oppose the one-child policy and argue from a moral perspective in terms of China's violation of human rights. Once the two groups debate the subject, the instructor should facilitate a discussion to clarify the facts. As a result, the students will learn an important principle of cultural immersion: you do not have to agree with what other countries have done, but you should understand why these policies are in place. As He and others believe, democracy, justice, equality, and toleration should be essential principles in understanding multiculturalism (He, Phillion, \& Connelly, 2005, p. 291). Thus, in preparation for courses related to cultural immersion and study abroad programs, librarians should be capable of identifying up-to-date information on the designated foreign country, providing in-depth cultural background, and preparing reading materials pertaining to today's multicultural environment. Meanwhile, it would be beneficial for students and the program if students could be on the outlook for useful resources while abroad, and bring back relevant resources from foreign countries in an effort to enrich the multicultural information in the library website.

As for in-country experience after the pre-trip workshop, the curriculum should focus on overcoming obstacles in making connections, making friends, dating, avoiding possible harassment situations, and understanding crosscultural adjustment. Specifically, students should learn nonverbal communications, such as eye contact, personal distance, nonverbal greetings, and body language (Paige, 2007, p.142). After all, "it is easy to be very open-minded, tolerant, and to talk about anti-racism when you are not interacting with people from different cultures." The real challenge is people's interaction in person for further integration work (Janhonen \& Palojoki, 2005, p. 367).

According to Merryfield (2003), in order to improve students' understanding of different cultures, she has "experimented with chats, threaded discussions, and listserv discussions" and discovered that she needs "to match the topic and goals of the assignments to the strengths of each technology." While chats work well, in Merryfield's view, listserv discussions can be cumbersome with large classes, but email within WebCT can be effective for group communication. Particularly, threaded discussion combines the best of classroom interaction with academic content. Also, new technology allows people to participate in the process of learning globally through exchanging cross-cultural ideas, perspectives, and interpretations.

Finally, post-trip reflection is necessary as the end of trip does not mean the end of a learning process. This post-trip program is designed to allow students to react to changes, assess what they have learned, appreciate different cultures, and engage in a long-term process of language and cultural learning (Paige, 2007, pp. 14). Most students use this post-trip reflection and debriefing as a forum to exchange their life-changing experience and discuss their future plans afterwards.

The popular format for this post-trip program is to invite all study abroad program participants to a debriefing workshop to share their experience and give feedback. This open forum will not only present what students have learned, but also educate other campus audience about the need and benefit of multicultural experiences. To increase the publicity for the workshop, librarians could identify hot issues related to a specific country or culture in order to foster a meaningful forum for debate among students and faculty. 
In conclusion, multicultural information is essential for a successful cultural immersion program. Librarians ought to play an important role in promoting experiential education through providing knowledgeable, sensitive, and concise online multicultural resources. Librarians' efforts have significantly improved the quality of cultural immersion curriculum and enhanced the level of multicultural understanding. The collaboration and integration of librarians, faculty, and students will effectively advance the excellence of multicultural research projects, cultural immersion instruction, and diversity awareness across campus.

\section{References}

Agosto, D. (2007). Building a multicultural school library: issues and challenges. Teacher Librarian, 34(3), 27-31.

Alexander, L. (2006). Multicultural materials course. Joint conference of librarians of color proceedings. Retrieved March 23, 2009 from http://www.nxtbook.com/nxtboks/hall erickson/jcl c 2006conf/index.php?statid $=126$

Connor, E. (2008). An introduction to instructional services in academic libraries. New York: Routledge.

Gorski, P. (2001). Multicultural education and the internet: intersections and integration. Boston: McGraw-Hill Higher Education.

Gray, K. S., Murdock, G. K., \& Stebbins, C. D. (2002). Assessing study abroad's effect on an international mission. Change (May/June), 47-51.

He, M. F., Phillion, J., \& Connelly, M. (2005). Narrative and experience in multicultural education. London: Sage Publications.

Institute of International Education. (2008). Open doors 2008: U.S. students studying abroad. Retrieved March 28, 2009 from http://opendoors.iienetwork.org

Janhonen-Abruquah, H., \& Palojoki, P. (2005). Good practice in multicultural Integration work in Finland: Collaborative learning in culturally sensitive projects. International Journal of Consumer Studies, 29(4), 359-370.

Kitsantas, A. (2004). Studying abroad: The role of college students' goals on the development of cross-cultural skills and global understanding. College Student Journal, 38(3), 441-452.

Kolb, A., \& Kolb, D. (2005). Learning styles and learning spaces: Enhancing experiential learning in higher education. Academy of Management Learning \& Education, 4(2), 193-212. 
Merryfield, M. (2003). Like a veil: Cross-cultural experiential learning online. Contemporary Issues in Technology and Social Studies Teacher Education, 3(2). Retrieved March 28, 2009 from http://www.citejournal.org/vol3/iss2/socialstudies/ article1.cfm

National Society for Experiential Education. (2009). Retrieved March 23, 2009 from http://www.nsee.org/about_us.htm\#sop

Paige, M., Cohen, A., Kappler, B., Chi, J., \& Lassegard, J. (2007). Maximizing study abroad: A students' guide to strategies for language and culture learning and use. Twin City, MN: University of Minnesota Press.

Pedersen, P. (2004). Experiences for multicultural learning. Washington, DC: American Psychological Association.

Purdue University Calumet. (2009). Retrieved April 6. 2009 from http://webs.calumet.purdue.edu/exl/types-ofexperiential-learning
Reimers, F. (2009). Educating for global competency. In J. Cohen, \& M. Malin. (2009). International perspectives on the goals of university basic and secondary education (pp. 183-202). New York: Routledge.

Scott, D. (2004). Foreword. Culture and learning: Access and opportunity in the classroom. Charlotte, NC: Information Age Publishing.

Tyler, M. (1999). Using media to create experiential learning in multicultural and diversity issues. Journal of Multicultural Counseling \& Development, 27(3), 153-165.

\section{Lan Shen}

Purdue University Calumet Library 10029 Somerset Drive, Munster, IN 46321 219-989-2678

shenlan@purduecal.edu 